\title{
APLIKASI ALAT POLISHING UNTUK KELOMPOK PENGRAJIN BATU AMBAR KECAMATAN TEMBALANG KOTA SEMARANG JAWA TENGAH
}

\author{
Aulia Windyandari' ${ }^{1}$ Hartono $^{2}$ \\ Departemen Teknologi Industri, Sekolah Vokasi, Universitas Diponegoro, \\ Jl. Prof. Soedarto, SH, Kampus Undip Tembalang, Semarang, Indonesia 50275 \\ Email: auliaw@undip.ac.id
}

\begin{abstract}
ABSTRAK
Permintaan pasar kerajinan batu ambar yang begitu besar membuat UKM "Amber Biru" masih kewalahan dalam mengejar proses produksi perhiasaan batu ambar.Peningkatan produktivitas diharapkan dapat dicapai melalui perbaikan pada proses polishing batu ambar. Perancangan alat yang menunjang proses penghalusan dan pengkilapan dilakukan dengan menggunakan penggerak dinamo seperti halnya mesin gerinda. Namun mata gerinda memiliki kekasaran yang tidak dapat digunakan sebagai alat poles, sehingga diperlukan proses modifikasi agar dapat memenuhi kebutuhan proses polishing dan pengkilapan yang berkualitas. Upaya pengembangan peralatan polishing dalam kegiatan pengrajin batu ambar di lingkungan UKM "Amber Biru" dan Kelompok Binaan-nya "Ambar Bulusan" menjadi fokus penelitian ini. Peningkatan produktivitas produksi perhiasan batu ambar akan dicapai melalui rancang bangun peralatan polishing yang handal, efisien dan ergonomis.
\end{abstract}

Kata kunci: Peralatan Polishing, UKM “Amber Biru”, UKM “Ambar Bulusan”

\begin{abstract}
Amber stone handycrafts market demand have a great potential. Therefore the UKM "Amber Biru" still overwhelmed in pursuit the production quantity. The increased productivity is expected to be achieved through improvements in the process of polishing amber. The design development of the polishing tools that support the process of smoothing and glazing was made by using the driving dynamo as well as grinding machines. However the grinding sand has roughness that might not be used as a polishing tool for the amber stone. Therefore the modifications was made to meet the needs polishing and glazing process quality. The aim of the research is to evaluate the application of the polishing equipment to improve the productivity of the amber stone handycratfs on the UKM"Amber Biru" and a group of amber craftments "Ambar Bulusan". The improvement of amber jewelry production productivity will be achieved through the design of reliable polishing tool.
\end{abstract}

Key words: Polishing equipment, UKM "Amber Blue", UKM "Ambar Bulusan" 


\section{PENDAHULUAN}

UKM "Amber Biru" dan kelompok binaan-nya "Ambar Bulusan" yang menjadi mitra dalam kegiatan ini berada di wilayah Kelurahan Tembalang, Kecamatan Tembalang, Semarang. UKM "Amber Biru" dalam hal ini sebagai mitra pertama yang sudah memiliki pengalaman dalam memproduksi kerajinan perhiasan dari batu ambar, sedangkan mitra kedua adalah Kelompok Binaan dari UKM "Amber Biru" yaitu "Ambar Bulusan" yang beranggota para pengrajin-pengrajin pengolahan batu akik dan batu ambar.

UKM “Amber Biru" memulai usahanya pada tahun 2010 berlokasi di Tembalang Regency, Kelurahan Tembalang, Kecamatan Tembalang. Tidak seperti produsenprodusen batu akik pada umumnya, "Amber Biru" memiliki ciri khas produk berupa produk-produk kerajinan yang terbuat dari batu ambar. Batu ambar tersebut diolah dirakit menjadi beberapa produk yang berupa kalung, liontin, tasbih, gelang ataupun produk kerajinan yang sejenis.

Proses produksi perhiasan batu ambar yang dilakukan oleh UKM "Amber Biru" dimulai dari proses pekerjaan pemotongan bahan baku yang kemudian dilanjutkan dengan pekerjaan penggosokan dan pembentukan awal. Pada pekerjaan penggosokan dan pembentukan awal diperlukan alat gerinda. Proses ini berfungsi untuk membentuk batu menjadi bentuk geometri awal yang diinginkan, seperti bentuk bola, hati dan tetesan air. Selanjutnya batu ambar memasuki tahapan proses penggosokan pemantapan, Pada proses ini bentuk potongan-potongan yang sudah dimodel sesuai desain yang dimaksud digosok sebagai pemantapan dan penyempurnaan bentuk geometri yang diharapkan. Tahapan selanjutnya adalah tahap penghalusan dan pengkilapan, proses polishing ini berfungsi untuk mengkilapkan batau-batu ambar, agar tampak cantik dan siap digunakan sebagai perhiasan. Pada tahapan akhir adalah pemeriksaan kualitas (kontrol mutu) dan finishing. Proses finishing adalah merangkai batu-batu ambar tadi menjadi gelang, liontin dan sebagainya sehingga produk batu ambar sudah siap untuk dipasarkan.

UKM “Amber Biru" selain memproduksi perhiasan batu ambar, juga terlibat dalam penjualan dan pemasaran produk-produknya. Pemasaran produk-produk UKM "Amber Biru" sudah menyebar sampai ke manca negara, seperti: China, Rusia, Korea, Jepang dan sebagainya. Aktivitas produksi perhiasan di UKM "Amber Biru” dapat dilihat pada Gambar. 1.
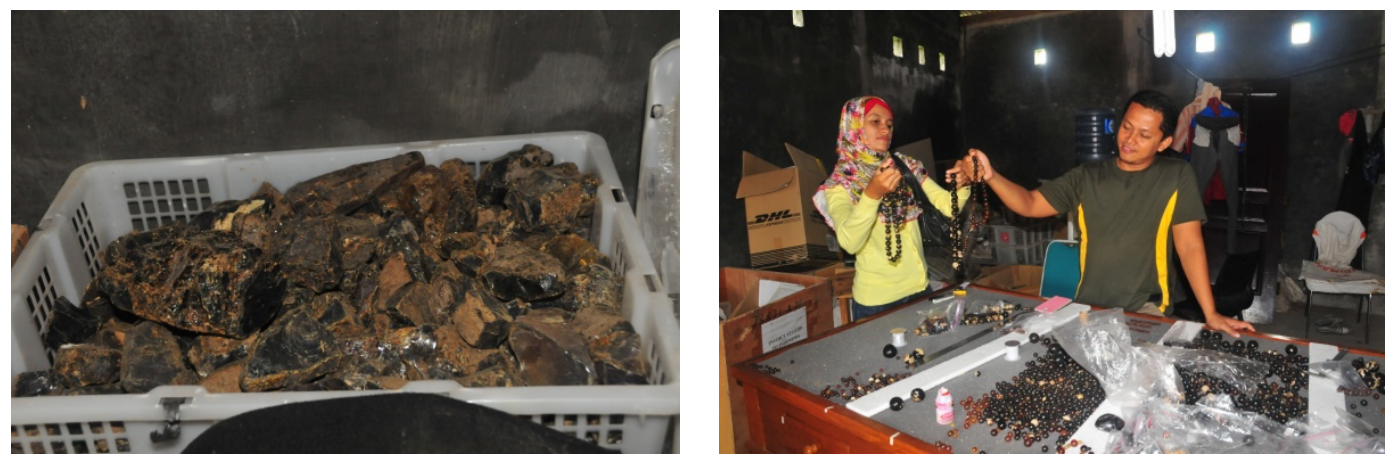

Gambar 1. Kegiatan observasi awal pada UKM “Amber Biru” 
Luaran yang dihasilkan dari penelitian ini adalah berupa produk peralatan polishing yang membantu dalam proses pengkilapan pada batu ambar yang menambah kecantikan kilau batu yang digunakan sebagai perhiasan. Perancangan alat yang menunjang proses penghalusan dan pengkilapan dilakukan dengan menggunakan penggerak dinamo seperti halnya mesin gerinda. Namun mata gerinda memiliki kekasaran yang tidak dapat digunakan sebagai alat poles, sehingga diperlukan proses modifikasi agar dapat memenuhi kebutuhan proses polishing dan pengkilapan yang berkualitas.

\section{TINJAUAN PUSTAKA}

Batu permata banyak dijadikan sebagai hiasan cincin ini mulai booming sejak akhir tahun 2014 hingga sekarang. Jika berlian, safir, dan zamrud adalah contoh dari precious stones, maka batu-batuan yang termasuk batu akik seperti kecubung, opal biru, garnet, dan sejenisnya adalah termasuk golongan semi-precious stones, [1]. Banyaknya jenis batu akik yang diperjualbelikan saat ini merupakan salah satu bukti kekayaan alam Indonesia. Selain batu akik terdapat jenis batu lain yang juga biasa digunakan sebagai perhiasan yaitu batu ambar atau amber stone.

Ambar atau amber adalah resin pohon yang menjadi fosil dan dihargai karena warna serta kecantikannya. Ambar berkualitas bagus digunakan dalam pembuatan barang permata dan ornamen. Meski tidak termineralisasi, ambar sering digolongkan sebagai sebuah batu permata. Ambar sering disalahpahami terbentuk dari getah pohon; padahal tidak. Getah adalah cairan yang bersirkulasi melalui sistem pembuluhnya tanaman, sedangkan resin merupakan substansi organik amorf setengah-padat yang dikeluarkan dalam kantung dan kanal (saluran) melalui sel epitelium pada tanaman, [2].

Sebagian besar amber di dunia ini berumur 30 sampai 90 juta tahun. Karena dulunya adalah resin pohon yang lunak dan lengket, kadang-kadang di dalam amber terdapat serangga dan bahkan hewan vertebrata yang kecil. Resin setengah terfosilkan atau amber sub-fosil dikenal sebagai kopal. Tidak hanya berwarna oranye kekuningkuningan, ambar memiliki warna yang beragam mulai dari keputih-putihan, kuning limau yang pucat, coklat, dan hampir hitam. Ambar berwarna merah (kadang-kadang dikenal sebagai "cherry amber"), hijau, dan biru termasuk langka dan sangat dicari-cari. Kebanyakan ambar yang bernilai tinggi memiliki permukaan transparan, tapi amber yang keruh dan gelap juga sangat umum. Amber yang permukaannya gelap berisikan sejumlah gelembung renik dikenal sebagai "bastard amber", meski kenyataannya ia adalah ambar sungguhan.

Cadangan batu ambar ditemukan di seluruh penjuru dunia. Cadangan ambar yang terkenal terdapat di negara-negara Baltik dan Republik Dominika. Beberapa ambar dipercaya berumur lebih dari 345 juta tahun (di Northumberland USA). Di Asia, ambar bisa ditemukan khususnya di Myanmar sebagai Burmit dan umurnya mencapai 50 juta tahun. Ambar Lebanon berumur 130 - 135 juta tahun lalu. Ambar Australia-Oseanik yang bisa ditemukan di Selandia Baru serta Pulau Kalimantan (Ambar Sawak) ada yang berumur 20 - 60 dan ada pula yang $70-100$ juta tahun, [3].

Di Asia, ambar bisa ditemukan khususnya di Myanmar sebagai Burmit dan umurnya mencapai 50 juta tahun. Ambar Lebanon berumur 130 - 135 juta tahun lalu. Ambar 
Australia-Oseanik yang bisa ditemukan di Selandia Baru serta Pulau Kalimantan (Ambar Sawak) ada yang berumur 20 - 60 dan ada pula yang 70 - 100 juta tahun.

\section{BAHAN DAN METODE}

Pada proses produksi perhiasan batu ambar, proses pengkilapan yang dilakukan tidaklah jauh berbeda dengan proses polishing yang dilakukan pada batu intan untuk menjadi sebuah berlian yang berkilau. Proses polishing umumnya dilakukan dengan menggunakan peralatan yang biasanya dimodifikasi sendiri oleh pengrajin, sesuai dengan pengalaman dan pengetahuannya sendiri. Ada yang menggunakan buluh bambu humbang sebagai alat penggosok. Ada juga yang menggunakan kain panen (sejenis sutra) untuk menggosok batu permata agar lebih mengkilap, [4].

Tujuan dari proses pengkilapan batu permata adalah memberikan finishing pada batu agar permukaan batu dapat memantulkan cahaya sehingga bisa tampak seperti sebuah cermin dan berkilau, selain pantulan cahaya juga menyempurnakan proses refraksi cahaya pada batu yang tembus cahaya, seperti: zamrud, safir dan intan. Pantulan dan refraksi yang sempurna dapat meningkatkan harga penjualan batu permata di pasaran.

Debu intan yaitu pada mesh 50.000 sampai dengan 100.0000 dapat digunakan sebagai bahan pengkilap untuk batu-batu permata. Bahan pengkilap yang lainnya adalah metal oxides (oksida logam). Oksida logam yang biasa digunakan seperti aluminum oxide (alumina), cerium oxide, tin oxide, chromium oxide, ferric oxide ataupun silicon oxide, [5]. Batu-batu yang berbeda memiliki karakteristik pengkilapan yang berbeda pula, sehingga para pengrajin batu seringkali mencoba teknik-teknik yang inventif dengan mencoba mengkombinasikan antara alat pengkilap dan permukaan yang dikilapkan, [6]. Pada batu permata berbentuk cobochons (bentuk geometri bundar yang biasa di temui pada batu cincin) biasa dikilapkan pada bahan flanel, kulit, cork, kain dan kayu. Pada batu permata bentuk facet (bentuk cutting seperti pada berlian) pengkilapan menggunakan timah, timah hitam, kulit, flanel, lain pellon, kayu atau lucite laps, [7]

Upaya perbaikan proses polishing dalam kegiatan pengrajin batu ambar di lingkungan UKM "Amber Biru" menjadi fokus usulan kegiatan penelitian ini. Peningkatan produktivitas dan kualitas polishing /pengkilapan perhiasaan batu ambar yang cepat dan berkualitas akan dicapai melalui beberapa target-target luaran yang terdiri dari:

- Alat prototipe untuk membantu pekerjaan polishing / pengkilapan yang sesuai dengan kebutuhan mitra yaitu UKM “Amber Biru" dan Kelompok Binaan "Ambar Bulusan"..

- Peningkatan kecepatan dan kualitas proses polishing dan pengkilapan diharapkan dapat meningkatkan produktivitas UKM “Amber Biru”. .

- Diperoleh suatu sistem operasi atau standar prosedur operasi untuk proses polishing / pengkilapan di UKM “Amber Biru”.

- Diperoleh suatu analisis ekonomi dengan adanya penambahan peralatan polishing / pengkilapan yang ergonomis.

- Diperoleh pemahaman pada pengrajin UKM “Amber Biru", tentang penggunaan dan manfaat alat polishing / pengkilapan mekanik, sehingga dapat meningkatkan kesadaran akan pentingnya inovasi peralatan untuk peningkatan produktivitas. 
Metode penelitian yang digunakan pada program ini diawali dengan melakukan evaluasi terhadap proses produksi batu ambar pada UKM “Amber Biru”, Kelurahan Tembalang, Kecamatan Tembalang, Semarang. Berdasarkan dari hasil survei awal tersebut, kemudian ditentukan tahapan-tahapan pelaksanaan kegiatan pengabdian masyarakat ini. Tahapan-tahapan pelaksanaan kegiatan tersebut dinyatakan dalam diagram alir yang dapat dilihat pada Gambar 2.

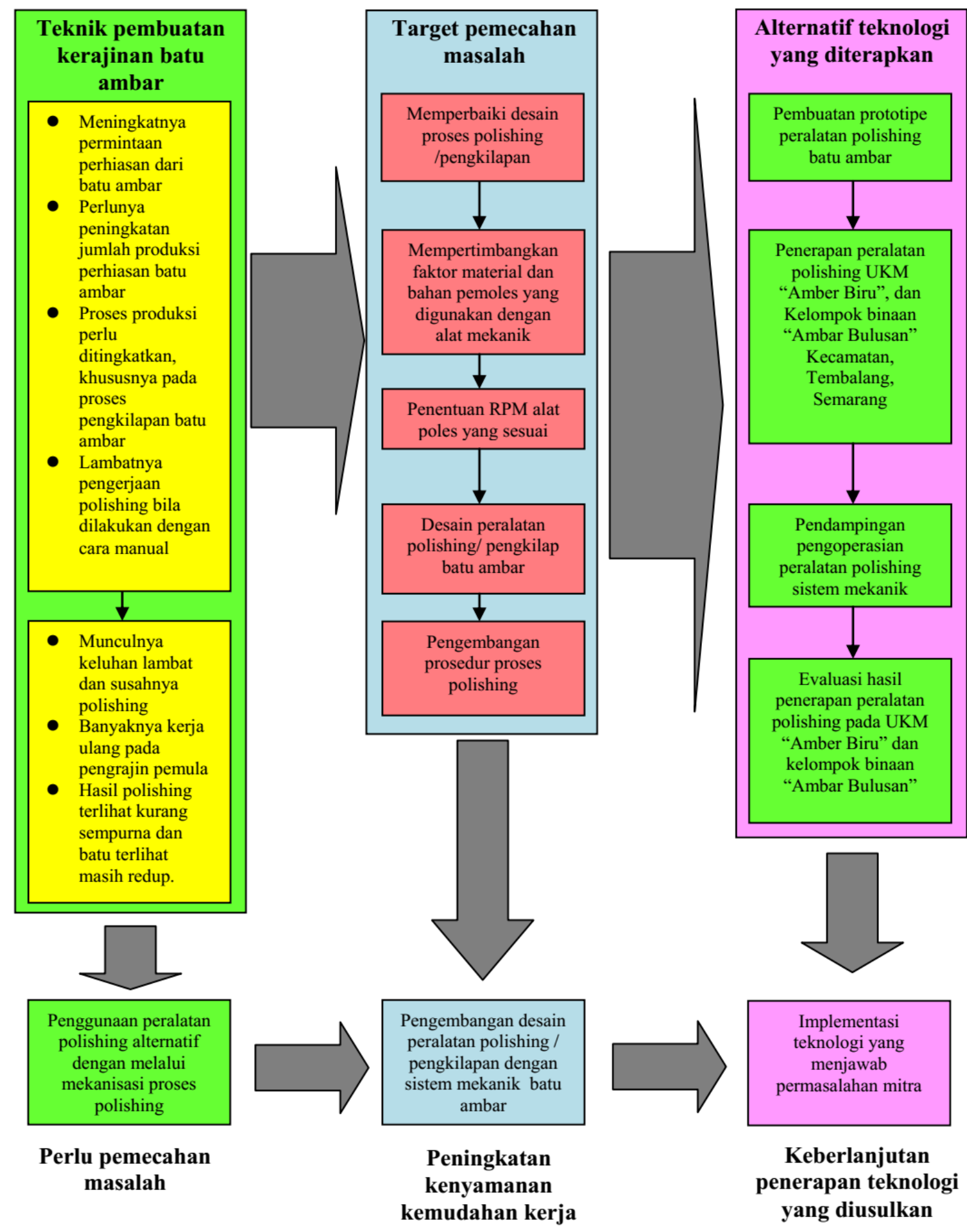

Gambar 2. Diagram alir metode pelaksanaan kegiatan penelitian 


\section{HASIL DAN PEMBAHASAN}

\section{Desain alat polishing batu ambar}

Pada tahapan ini telah dikembangkan desain alat polishing bagi para pengrajin batu ambar. Desain alat polishing disesuaikan dengan kebutuhan pengrajin batu ambar dalam memoles batu ambar. Alat ini memiliki bagian yang berputar terus menerus dan bagian ini sudah dilapisi oleh serbuk intan, bagian ini berguna sebagai tempat memoles batu. Alat ini mempunyai kelebihan dibanding dengan polishing manual, lebih cepat dan dapat meminimal kerusakan pada batu ambar. Sifat batu ambar yang mudah pecah dan mudah tergores mengakibatkan banyak masalah pada saat memoles dengan cara manual. Dengan adanya alat polishing masalah tersebut dapat dihindarkan karena pengrajin batu ambar dapar mengontrol kecepatan putar alat sesuai dengan kebutuhan pemolesan.

Pada pengembangan desain alat polishng lebih mengutamakan pada kemampuan dan kontrol alat dalam berputar sehingga mudah dilakukan proses pemolesan oleh pengrajin batu ambar. Desain polishing tidak berhubungan langsung terhadap potensi terjadinya cidera pada pengrajin batu ambar, namun lebih ditekankan pada kebutuhan panjang dan ketinggian untuk meletakkan batu ambar yang sedang poles pada proses polishing.

\section{Perakitan alat polishing batu ambar}

Desain yang telah dikembangkan selanjutnya dilakukan pembuatan. Pada proses pembuatan alat polishing dilakukan oleh tenaga-tenaga terlatih dan terampil sehingga produk yang dihasilkan benar-benar sesuai dengan desain yang telah dikembangkan. Tingkat kemajuan dari proses pembuatan masih pada tahapan pembuatan alat polishing, dilihat pada Gambar 3.
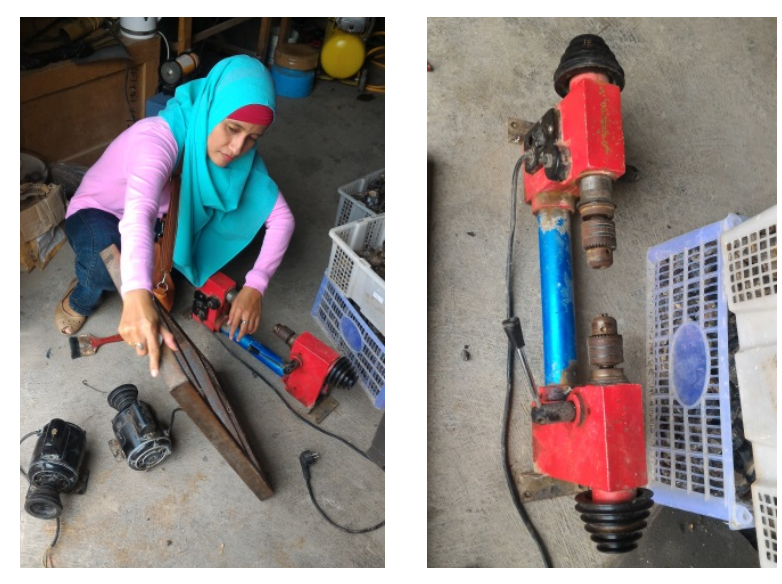

Gambar 3. Pembuatan alat polishing

\section{Finishing alat Polishing}

Pada tahap berikutnya akan dilanjutkan pembuatan meja dudukan polishing, sehingga pengrajin batu ambar menjadi lebih nyaman dalam melakukan aktifitas pada proses pemolesan. Setelah itu proses finishing dilakukan pada alat polishing. Proses ini dilakukan agar produk yang dihasilkan memenuhi kualitas yang diharapkan oleh pengguna produk yaitu para pengrajin batu ambar. Selain mempercantik produk, proses finishing juga membantu melindungi produk agar lebih awet dan tahan lama. 


\section{Penerapan produk yang telah dikembangkan pada UKM "Amber Biru"}

Produk alat polishing selanjutnya diberikan kepada mitra UKM agar digunakan oleh para pengrajin batu ambar di tempat kerjanya. Pendampingan pada penerapan produk dilakukan agar produk yang dihasilkan sesuai dengan prosedur penggunaan produk. Selain itu pada proses pendampingan juga dilakukan umpan balik dari pengguna produk untuk perbaikan dan masukan bagi perancang produk.

Berdasarkan pengamatan dan hasil wawancara yang dilakukan oleh tim pengabdian, alat polishing yang dikembangkan untuk perbaikan sistem produksi kerajinan batu ambar telah menunjukkan hasil perubahan yang baik, lihat Tabel 1. Para pengrajin batu ambar merasa bahwa dengan alat polishing baru ini hasil pengkilapan lebih bagus sehingga kualitas produk dari pengrajin semakin lebih baik. Adapun desain dan hasil akhir alat polishing yang dikembangkan dapat dilihat pada Gambar 4:

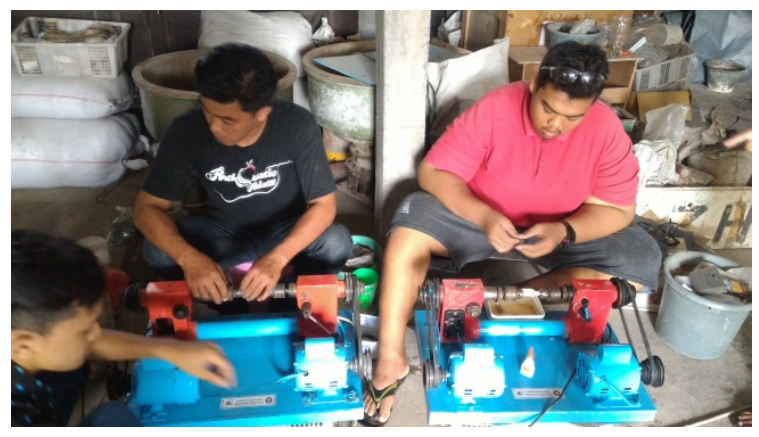

Gambar 4. Penerapan produk alat polishing pada UKM “Amber Biru”

Tabel 1. Perubahan akibat penerapan alat polishing

\begin{tabular}{l|lcc}
\hline No & Uraian & Sebelum diaplikasikan & $\begin{array}{l}\text { Sesudah } \\
\text { diaplikasikan }\end{array}$ \\
\hline 1 & $\begin{array}{l}\text { Meningkatnya kecepatan } \\
\text { proses polishing / } \\
\text { pengkilapan }\end{array}$ & 5 biji /hari & 25 biji/hari \\
2 & $\begin{array}{l}\text { Meningkatnya jumlah } \\
\text { produksi perhiasan batu } \\
\text { amber }\end{array}$ & 20 unit/bulan & 50 unit/bulan \\
\hline
\end{tabular}

\section{KESIMPULAN}

Kegiatan penelitian aplikasi alat polishing untuk kelompok pengrajin batu ambar kecamatan tembalang kota semarang jawa tengah telah dilaksanakan. Pengembangan desain dan alat polishing telah dikembangkan dan diaplikasikan pada mitra UKM "Amber Biru". Hasil menunjukkan bahwa alat polishing telah memberikan peningkatan kualitas khususnya dalam proses pengkilapan produk perhiasan batu ambar. Peningkatan kualitas pengkilapan dan kurangnya resiko batu pecah yang ditawarkan diharapkan mampu memperbaiki proses produksi perhiasan batu ambar serta mengurangi keluhan rendahnya kualitas kilap batu ambar dan kerugian akibat pecahnya batu pada proses polishing. Peningkatan produktivitas dan peningkatan kualitas dapat dicapai dengan proses pengkilapan (polishing) di tempat mitra UKM"Amber Biru". 


\section{DAFTAR PUSTAKA}

[1] Anonim, 2015. "Tren Batu Akik: tiga hal yang wajib kamu tahu", diakses dari situs nanonesia (http://nanonesia.com/populer/tren-batu-akik-3-hal-yang-wajib-kamutahu/)

[2] Anonim, 2015. "Khasiat batu fosil getah damar atau amber (ambar)", diakses dari situs permataku.biz (http://permataku.biz/blog/khasiat-batu-fosil-getah-damaratau-amber-ambar

[3] Anonim, 2015. "Ambar (batu Ambar)", diakses dari situs wikipedia (http://id.wikipedia.org/wiki/Ambar)

[4] Anonim, 2015. "How are Gems Cut and Polished", diakses dari situs tradeshop (http://www.tradeshop.com/gems/howcut.html)

[5] Rubin and Son. 1992. "Machinery and Tools for Diamond Industry". Belgium

[6] Raudatul Jannah, 2013.”Pengembangan Pariwisata Kerajinan Batu Aji, Batu Permata dan Batu Mulia di Kabupaten Banjar. Makalah Seminar pada Kantor Perwakilan Bank Indonesia Wilayah Kalimantan tanggal 18 Juni. Banjarmasin

[7] Anonim, 2013. “ Kerajinan Penggosokan intan dan batu permata martapura”. Kantor perwakilan Bank Indonesia wilayah Kalimantan 